\title{
Tertúlias Dialógicas Virtuais: integrando tecnologias digitais, leitura e literatura num contexto de Blended Learning na EJ A
}

\author{
Evandro Alves ${ }^{1}$ \\ Roselaine Aquino da Silva ${ }^{2}$ \\ Carla Cristóvão Balena ${ }^{3}$ \\ Dione Maria Busetti ${ }^{4}$ \\ Camila Prates ${ }^{5}$
}

\section{Resumo}

A disseminação do emprego das Tecnologias da Informação e Comunicação (TICs) na Educação, sobretudo a referente às tecnologias digitais, traz novas possibilidades a práticas educacionais em diferentes contextos, inclusive, na Educação de Jovens e Adultos (EJA). Um dos efeitos de tal disseminação é uma constante reflexão acerca das práticas pedagógicas em uma perspectiva teoricometodológica, para que essas sejam cada vez mais sensíveis à utilização e integração das Mídias. O presente texto visa relatar uma experiência nesta direção na área da EJA, em específico sobre uma prática consolidada na área: a "tertúlia literária dialógica". Em linhas gerais, trata-se de um círculo de leitura que congrega alunos e professores em torno de um texto escolhido, no contexto das tecnologias digitais. Nesse sentido, um dos desafios foi de como pensar essa prática na conexão com as mídias e com as TICs, adicionando-Ihe componentes da virtualidade referente ao uso das tecnologias digitais. A edição das tertúlias dialógicas virtuais relatada neste trabalho aconteceu durante o ano de 2008, com um grupo de alunos e professores do ensino fundamental no Centro Municipal de Educação do Trabalhador Paulo Freire, do município de Porto Alegre. Os resultados apontam para a positividade de ações deste tipo, na medida em que qualificam ainda mais o ingresso dos alunos, não somente à cultura escrita, mas também à cultura informatizada e à cibernética, num contexto que congrega características de blended learning, no qual atividades online e offline e ambientes presenciais e a distância, antes de serem antagônicos, se complementam na prática pedagógica.

\section{ABSTRACT}

The dissemination of employment of Information and Communication Technologies (ICT) in education, especially digital technologies, offers new opportunities to educational practices in different contexts, including in the young and adult education. One of the effects of such dissemination is a constant reflection of pedagogical practices, from the point of view theoretical and methodological, so that these are more sensitive to the use and integration of medium. This

\footnotetext{
${ }^{1}$ Doutor e Mestre em Educação (UFRGS).Licenciado em Pedagogia. Pesquisador LELIC/UFRGS.

${ }^{2}$ Doutora em Educação - Universidade de Barcelona. Coordenadora Pedagógica CMET Paulo Freire Professora da rede municipal de Porto Alegre.

${ }^{3}$ Bacharel em Direito. Graduanda em Artes Plásticas (UFRGS). Professora da rede municipal de Porto Alegre.

${ }^{4}$ Licenciada em Letras. Especialista em EJA. Coordenadora Pedagógica CMET Paulo Freire. Professora da rede municipal de Porto Alegre.

${ }^{5}$ Graduanda em Pedagogia (UFRGS). Pesquisadora LELIC/UFRGS
} 
text aims at reporting a these thoughts, in particular on a consolidated practice in the area of young and adult education: the "literacy dialogical circle" (tertúlia literária dialógica), in general, a reading circle which brings together pupils and teachers around a text chosen, in the context of digital technologies. In this sense, one of the challenges was how to think of this practice in connection with the media and ICT by adding components of virtuality regarding the use of digital technologies. The "literacy dialogical assemble" reported here occurred during the year 2008, with a group of students and teachers in the Municipal Center Worker's Education Paulo Freire (Porto Alegre, Brazil). The results point to the positive actions of this kind, in that further qualify the admission of students, not only to written culture, but also to the computer and cybernetics culture, in an environment with characteristics of blended learning, in which elements and online and offline, classroom and e-learning, previously considered antagonistic, are now additional element in the pedagogical practices.

\section{Apresentação}

O presente artigo objetiva sistematizar algumas reflexões sobre o emprego da tecnologia em projetos educacionais voltados para alunos do ensino fundamental da área de Educação de Jovens e Adultos (EJA), em um contexto específico: a reconfiguração de uma prática corrente na área, as tertúlias literárias dialógicas, para um contexto conectado com virtualidade propiciada pelo emprego de sistemas informatizados e cibernéticos. Tal reconfiguração implicou um movimento de combinação e harmonização de estratégias que se valiam da presencialidade e da atividade a distância, de atividades online e offline para a consecução do projeto. Esse movimento acabou guardando algumas características do chamado blended learning, já usual e com efeitos analisados no ensino superior, conforme apontam os estudos de Donnely (2010), mas com poucos relatos no contexto da EJA. denominamos Denominamos de Tertúlias Dialógicas Virtuais a essa combinação e harmonização de ambientes e estratégias de compartilhamento de saberes e de ensino-aprendizagem, a ser detalhada nas seções seguintes.

\section{Contexto da experiência}

O projeto Tertúlias Dialógicas Virtuais vem sendo realizado no Centro Municipal de Educação do Trabalhador Paulo Freire (CMET Paulo Freire), vinculado à Secretaria Municipal de Educação de Porto Alegre desde de 2008. Este trabalho relata as atividades referentes ao primeiro ano de atividade do projeto.

Em 2008, as tertúlias dialógicas foram organizadas no CMET Paulo Freire na forma de oficina cultural, com periodicidade semanal, em sessões de 90 
minutos, no laboratório de informática da instituição, que conta com 15 computadores ligados a um servidor. O grupo de trabalho, formado por adesão, foi constituído por 12 alunos de diversas etapas do ensino fundamental da EJA. A equipe de planejamento e intervenção pedagógica contou com três professores da instituição e dois pesquisadores do Laboratório de Estudos em Linguagem, Interação e Cognição da Universidade Federal do rio Grande do Sul (LELIC/UFRGS).

A Tertúlia Dialógica Virtual, por sua vez, é uma ação de um projeto de intercâmbio entre grupos de alunos e professores da EJA do CMET Paulo Freire e a Escola La Verneda de Sant-Martí, (Barcelona/Espanha). Esse projeto recebe, na instituição portoalegrense, o nome de Sem Fronteiras. Desde 2003, o projeto de intercâmbio engendra ações na direção do estabelecimento de diálogos interculturais entre as instituições de Porto Alegre e Barcelona. Em torno deste projeto vem sendo desenvolvidas no CMET, além das Tertúlias, mostras culturais desenvolvidas pelos alunos sobre sua cultura e sobre a cultura espanhola, oficinas de língua espanhola para o grupo de alunos, intercâmbio de docentes e alunos, etc. O projeto Sem Fronteiras, desde os seus primórdios, utiliza de recursos de EAD para a consecução de suas atividades, utilizando, para conectar alunos e professores, sobretudo, troca de mails, chats e webconferências.

Em 2008, no contexto do projeto de intercâmbio Sem Fronteiras, surgiu a ideia de desenvolver no CMET Paulo Freire uma prática de leitura compartilhada de clássicos universais, denominada Tertúlia Literária Dialógica, cuja metodologia específica é consolidada no âmbito da EJA e será detalhada na revisão de literatura.

O desenvolvimento deste projeto tornou o grupo do CMET integrante de uma rede de instituições de EJA que realizam tertúlias em vários países e que compartilham suas experiências de leitura uma atividade denominada Mil y Una Tertulias Literarias Dialógicas por Todo el Mundo. Essa atividade é promovida pela Confederação de Federações e Associações de Participantes em Educação e Cultura Democrática de Pessoas Adultas - CONFAPEA - 
(Barcelona/Espanha). A proposição da atividade "Mil y Una Tertulias..." era a de que os grupos que participassem desta rede de tertulias, espalhados pelo mundo, realizassem a leitura de um texto escolhido e que essas experiências de leitura pudessem ser compartilhada ao final do ano, através de webconferência. O texto escolhido foi A Casa de Bonecas, peça do século XIX, de autoria de Henrik Ibsen.

À parte a questão babélica do evento, em que se optou pela convivência pacífica da diversidade dos idiomas na atividade, (de um lado, talvez entenderíamos pouco ou muito dos outros grupos integrantes; mas, de outro lado, tomaríamos contato com outros idiomas, visto estarmos lendo o mesmo livro), o desenvolvimento do intercâmbio de experiência do CMET com grupos de outros países, do ponto de vista metodológico, trazia questões importantes.

- Do ponto de vista da prática de leitura, como fazer um grupo de alunos jovens e adultos de diversas etapas do nível fundamental de ensino, muitos dos quais com problemas de leitura e interpretação de textos, aproximar-se da leitura de um texto clássico?

- Do ponto de vista do emprego das TICs na Educação, como desenvolver um trabalho pedagógico com as Tertúlias que levasse os alunos de meros participantes de uma webconferência, da qual eles falariam sobre suas experiência de leitura em poucos minutos? Como trazer a questão das TICs de seu papel circunstancial para ser componente relevante para a consecução do projeto?

Essas questões metodológicas foram discutidas entre docentes do CMET envolvidos no projeto e pesquisadores do LELIC. Em parte, a própria metodologia de desenvolvimento das Tertúlias Literárias Dialógicas acabou contribuindo para o encaminhamento das atividades. Mas a adaptação da metodologia para a realidade do grupo e os objetivos de incorporarem as TICs no trabalho implicaram:

1) o ordenamento de atividades na oficina que trouxessem gradativamente os alunos à leitura e, especificamente, à estrutura de texto da leitura proposta: uma peça de teatro. 
2) a utilização de atividades envolvendo direta ou indiretamente as tecnologias digitais que colocassem os alunos em uma situação de produtores e leitores de narrativas;

3) o emprego e parcial ressignificação de ferramentas online, no caso específico deste relato, de um blog, para fomentar/apresentar a produção do grupo em torno da leitura.

O dimensionamento do trabalho pedagógico entorno das tertúlias dialógicas virtuais, ocorrido no CMET Paulo Freire, em nosso entendimento, acaba por assumir características, guardadas as devidas proporções, do que denomina, no âmbito da Educação a Distância, de blended learning. Tal assunção se daria, sobretudo, no que diz respeito à harmonização entre estratégias e ambientes de ensino-aprendizagem, em que atividades online e offline, presenciais e distância se complementem mutuamente no contexto da prática pedagógica.

Tal apontamento metodológico, ainda segundo nosso entendimento, contribuiria para uma articulação entre o uso das tecnologias na Educação e da Educação a Distância e os princípios de uma Educação Dialógica, um dos princípios fundamentais da Educação Popular, conforme descrito o pensador pernambucano Paulo Freire (2005).

\section{Revisão de Literatura}

\section{Tertúlias Literárias Virtuais}

O termo tertúlia tem origem espanhola. Existe no português do Brasil, mas é pouco empregada, à exceção dos estados da região sul do país. Conforme Houaiis (2009), tertúlia significa "reunião para discutir ou conversar". Encontrase, na significação em língua portuguesa, um direcionamento para a questão literária, pois significa também palestra ou pequena agremiação literária. Em português, é mais comumente usado o termo "sarau" para encontros desta natureza.

Tertúlia Literária é prática consolidada na EJA. Segundo Flecha e Mello (2005), suas origens literárias remete aos anos 1970, quando das mudanças da 
Educação de Jovens e Adultos na Espanha de um modelo compensatório para um modelo democrático e emacipatório. Neste contexto, funda-se a Escola de Educação de Pessoas Adultas de La Verneda de Sant-Martí, em Barcelona. Nessa instituição cria-se, na década de 1980, uma metodologia de trabalho pedagógico em torno da prática de leitura compartilhada, denominada de tertúlias literárias. Na década de 1990, outras instituições e escolas espanholas passam a exigir a atividade como integrante de sua formação, dado seu caráter dialógico e transformador. A atividade, então, passa a se denominar Tertúlias Literárias Dialógicas. Atualmente, a difusão da metodologia que envolve as tertúlias literárias dialógicas vem sendo promovida pela CONFAPEA através do projeto "Mil y Una Tertulias Literarias Dialógicas por Todo el Mundo" (Mello, 2004), já mencionada neste trabalho.

Do ponto de vista tericometodológico, Mello (2004) decreve que os aportes fundamentais para a constituição da metodologia das Tertúlias Literárias Dialógicas são, no campo educacional, o pensamento de Paulo Freire e, no campo das ciências sociais, a razão comunicativa de Habermas. Assim, tratase de uma atividade que:

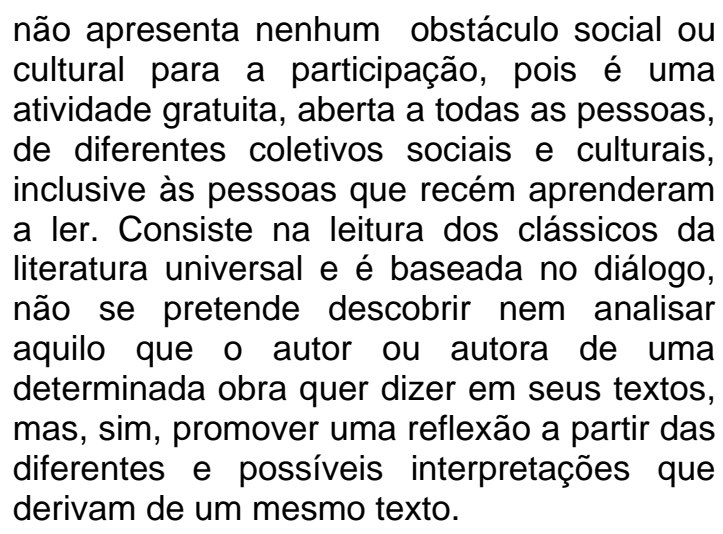

Segundo Flecha e Melo (2005), a metodologia desenvolvida nas tertúlias se ancora em sete princípios indissociáveis. A tertúlia literária dialógica objetiva: (1) a promoção do diálogo igualitário, (2) o reconhecimento da inteligência cultural, (3) a prática da leitura voltada à transformação pessoal e social; a não oposição, na prática de leitura, entre (4) a construção de conhecimento e a (5) produção de sentidos, (6) o fomento à solidariedade pelo compartilhamento de saberes e (7) igualdade no direito à diferença. 
No Brasil, as tertúlias dialógicas vêm sendo realizadas por alguns grupos, dentre os quais mencionamos o Núcleo de Investigação e Ação Social e Educativa da Universidade Federal de São Carlos (NIASE/UFSCAR). Trabalhos envolvendo tertúlias dialógicas vêm sendo desenvolvidos com crianças e adolescentes (Girotto, 2007) e envolvendo outros produtos culturais além da literatura, como a utilização de obras musicais, conforme aponta Chaib (2003).

Quanto ao uso das tecnologias digitais, encontramos o desafio proposto no site de outra entidade catalã voltada à Educação de Jovens e Adultos - Federació d'Associacions Culturals i Educatives de Persones Adultes - FACEPA (2008). Trata-se de um manifesto em favor da utilização das tecnologias de informação e comunicação, dentre elas as digitais, de forma que os usuários deixem de ser receptores e passem, cada vez mais, a ser gestores da informação e produtores de conteúdo. A experiência relatada neste artigo visa a ser um esforço metodológico neste sentido, ao propor a adaptação de uma prática em voga na EJA à realidade do grupo de alunos do CMET Paulo Freire, na conexão com a utilização de tecnologias digitais. Para tanto, apontamos como válidos alguns princípios advindos do que se denomina atualmente, no campo da Educação a Distância, de blended learning, porém com conceituação adaptada a natureza do projeto relatado.

\section{Blended Learning}

Segundo a definição preconizada por Grahan (2004), três definições de fundo delineariam o conceito de blended Learning (aprendizagem "mesclada"): 1) combinação de modalidades de aprendizagem, do ponto de vista das mídias; 2) combinação métodos instrucionais e 3) combinação de ações online com ações presenciais. O autor aponta a terceira definição como a mais precisa, por suplantar a dicotomia entre mídia e método de aprendizagem. Em outras palavras, trata-se da combinação, de componentes de educação a distância e presenciais, em uma prática pedagógica, para a melhor consecução dos objetivos pedagógicos. Cada vez mais autores vêm escrevendo sobre o tema (Pina, 2008; Mcdonald, 2008) e estratégias de ensino-aprendizagem nessa 
perspectiva vêm sendo desenvolvidas neste sentido, sobretudo no Ensino Superior. Contudo, autores como Grahan (idem) e Macdonald (idem), ao mesmo tempo em que apontam as possibilidades do blended learning, também apontam suas fragilidades.

Cabe ressaltar que não é objetivo deste artigo tentar enquadrar a experiência das Tertúlias Dialógicas Virtuais, cujo público-alvo é um grupo da EJA cursando o ensino fundamental, como sendo um caso de blended learning com as mesmas características que ocorrem no Ensino Superior. Ainda que no projeto de intercâmbio Sem Fronteiras, as instituições de EJA espanhola e brasileira façam uso de ferramentas de interação síncrona e assíncrona no desenvolvimento de suas atividades, também não é objetivo deste artigo não enquadrá-lo como sendo uma ação característica de blended learning.

Conforme disposto no título do trabalho, gostaríamos de identificar o trabalho realizado nas Tertúlias Dialógicas Virtuais tendo, por pano de fundo, aspectos do Blended Learning que contextualizam as escolhas metodológicas realizadas. Esses aspectos dizem respeito:

- à articulação entre atividades presenciais, offline e online para a consecução das atividades;

- à importância da harmonização entre tecnologia e interações pretendidas na atividade pedagógica (Donelly, 2010);

- à aderência entre o uso das tecnologias e os pressupostos pedagógicos do projeto Tertúlias Dialógicas Virtuais.

Na próxima seção, buscaremos apresentar as escolhas realizadas e alguns resultados práticos obtidos.

\title{
As tertúlias dialógicas virtuais no CMET Paulo Freire
}

\author{
Estabelecimento da dinâmica e atividades
}


A oficina Tertúlias Dialógicas Virtuais iniciou em abril de 2008 e tinha um caráter preparatório para a webconferência, que se realizaria em novembro do mesmo ano, colocando em contato síncrono os diversos grupos que realizaram suas tertúlias tendo por livro-base a peça A Casa de Bonecas, de Henrik Ibsen.

O primeiro ponto era como articular uma dinâmica em que: (1) os alunos se apropriassem da leitura e a discutissem e que (2) conseguissem utilizar as tecnologias digitais como uma forma de expressar os sentidos que a leitura compartilhada produziu, em sessões semanais de 90 minutos. Outra decisão foi realizar as atividades no laboratório de informática do CMET Paulo Freire, para aproveitar o tempo e realizar as atividades envolvendo tecnologias digitais no mesmo espaço em que a discussão sobre as leituras escolhidas ocorreria.

Quanto à carga de leitura da oficina, acabamos optando por não ir direto ao texto Casa de Bonecas, pois era um volume bastante extenso para um grupo de EJA que, em linhas gerais, apresentam dificuldade de leitura e de escrita mesmo em fases finais do ensino fundamental. Além disso, o volume escolhido apresentava outra especificidade: ser uma peça de teatro, com marcações de cena e marcas de diálogo entre personagens.

Nossa opção foi a de dividir a oficina em dois momentos, cada um com duração de um semestre letivo, da seguinte maneira:

\section{Tertúlia Dialógica Virtual - Atividades Primeiro semestre 2008}

- Objetivo: aprimorar, através de textos curtos, a dinâmica da tertúlia, objetivando a preparação para a leitura do livro Casa de Bonecas.

- Dinâmica: faríamos leituras de contos e crônicas, objetivando uma aproximação ao gênero narrativo escolhido para a atividade "Mil y una Tertulias...": uma peça teatral. Ao mesmo tempo, testávamos a dinâmica a fim de delinear aprimoramentos para um texto de maior fôlego. O planejamento ia alternando a rotina 1 e a rotina 2 , na medida da necessidade e do interesse dos alunos.

Dentre a lista de autores e textos trabalhados durante o primeiro semestre de atividades nas tertúlias, destacam-se:

Stanislaw Ponte-Preta - crônica "Éramos Mais Unidos aos Domingos";; Mário Prata - crônica "O celular, quem diria, virou cafona";* Luís Fernando Veríssimo - Crônicas "O casamento" e "O lixo"

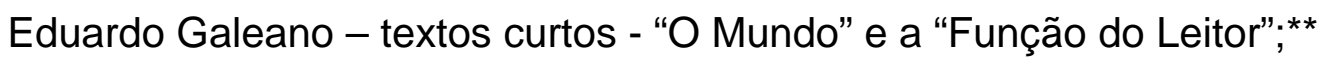


Carlos Drummond de Andrade - "E agora José...";***

Mario Quintana - "Eu escrevi um poema triste"****

Referências

* Texto retirado PROJETO RELEITRAS: http://www.releituras.com/index.asp

** VERÍSSIMO, L.F. Analista de Bagé. Porto Alegre: LPM Editora. 1982

*** GALEANO, E. Livro dos Abraços. Porto Alegre: LPM Editora. 2002

**** Texto extraído do site Memória viva http://www.memoriaviva.com.br/drummond/index2.htm

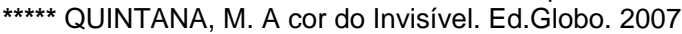

\section{Rotina 1}

- Num primeiro momento, era realizada a leitura de textos curtos, que permitissem ser lidos durante o enconto, discutidos. Num segundo momento, encaminhava-se o trabalho no laboratório, com utilização de softwares ou consultas na internet a algum assunto que tivesse sido mencionado na leitura ou discutido pelo grupo. Como resultantes desta proposta, os produziam atividades, como, por exemplo a construção de diálogos usando template em BrWriter voltado para esse fim (figura 1) ou a construção de um poema (Figura 2). Ao final, socializávamos os trabalhos realizados e os achados com o grupo. No encontro seguinte, trabalhava-se outro texto ou continuava-se com o mesmo da semana anterior, dependendo da recepção dos alunos, buscando incrementar, no caso de uma retomada, com algum material hipermidiático ou

\section{Rotina 2} audiovisual que estivesse conectado ao texto e enriquecesse.

- Realização de atividade envolvendo tecnologias digitais e questão de narrativas (atividade de construção de história em quadrinhos o software hagaqué - Figura 3 - ou do interesse dos alunos, como construção de slide-show com mensagens usando o Brlmpress, etc.).

\section{Notas}

1) Com o tempo, fomos descobrindo a importância do momento inicial de "conversa" do grupo. Era um movimento que, simultaneamente, aglutinava os participantes do grupo e, de certa forma, "preparava" a leitura do texto escolhido. Os ministrantes da oficina tinham de trabalhar para fazer o grupo "voltar" ao cronograma, sob pena de não realizar as atividades propostas.

2) O trabalho com textos curtos e de humor teve bastante resultado, pois o riso "agregava" o grupo e parecia facilitar a troca de experiências. Líamos silenciosamente e depois cada um de nós lia um trecho do escrito. Após, trocávamos nossas impressões sobre o texto lido e realizávamos os trabalhos com as tecnologias digitais que haviam sido planejados de forma conectada à leitura realizada. 


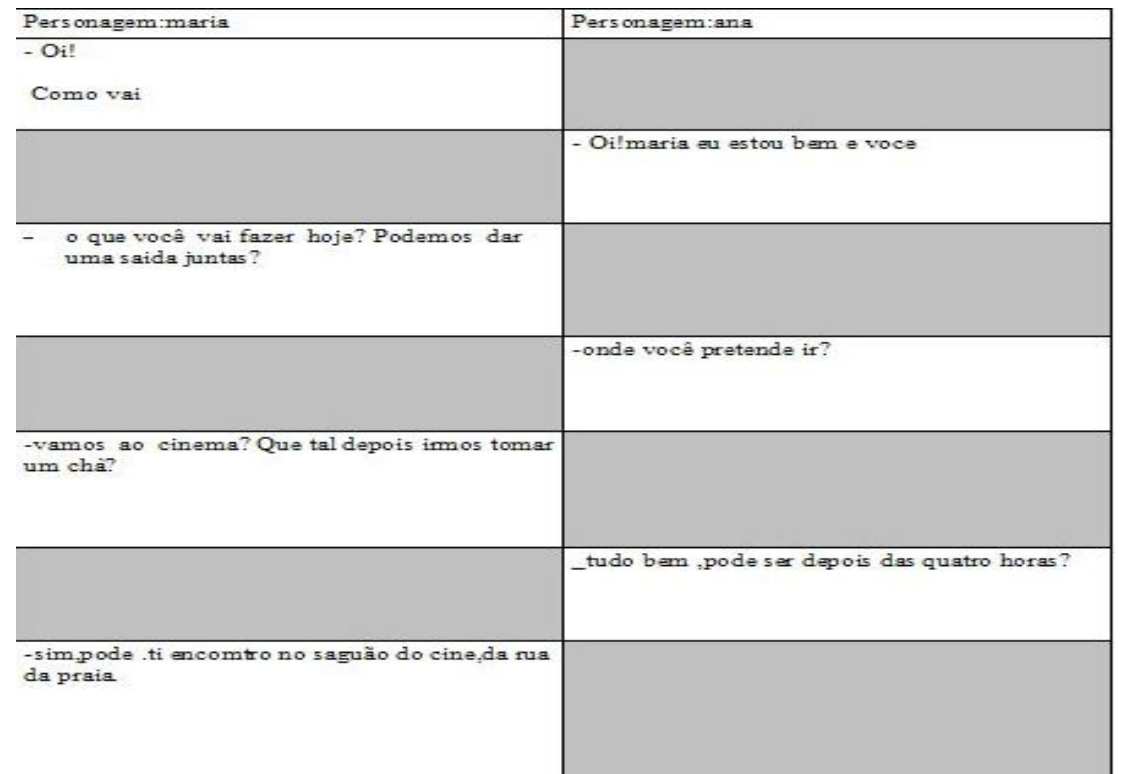

Figura 1 - Trabalho de construção de diálogo narrativo realizado pelos alunos da tertúlia utilizando template em BrWriter elaborado para este fim.

SAUDADE

PENSAR NAS COISAS RUIM É SOFRER DUAS VEZES PENSAR NAS COISAS BOAS FAZ BEM

VAMOS PENSAR EM FLORES E CULIIVA LAS

ANTONIO ARMANDO SOUZA
Vim correndo pela rua por que estava atrasada vim olhando para lua e tropiquei na calçada sem olhar para rua maria $\mathrm{m} \mathrm{m}$

\section{Poema feliz} poema feliz e a felicidade nas rosas fei tas de papel

luis ademar

$2 A$

2C

Figura $2-2 A, 2 B$ e 2C. Exemplos de poemas elaborados pelos alunos, resultantes de atividade das tertúlias dialógicas virtuais.

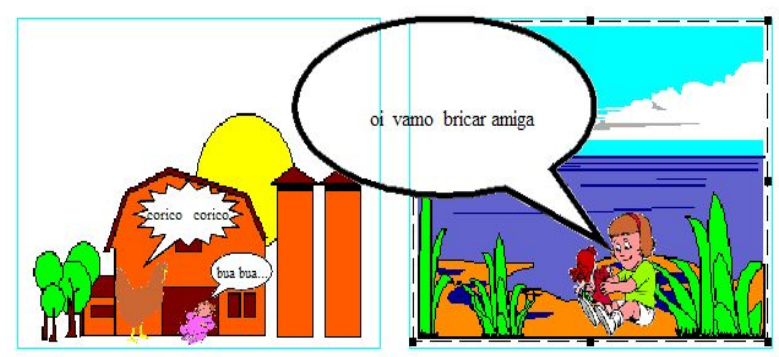

$3^{\mathbf{a}}$ 

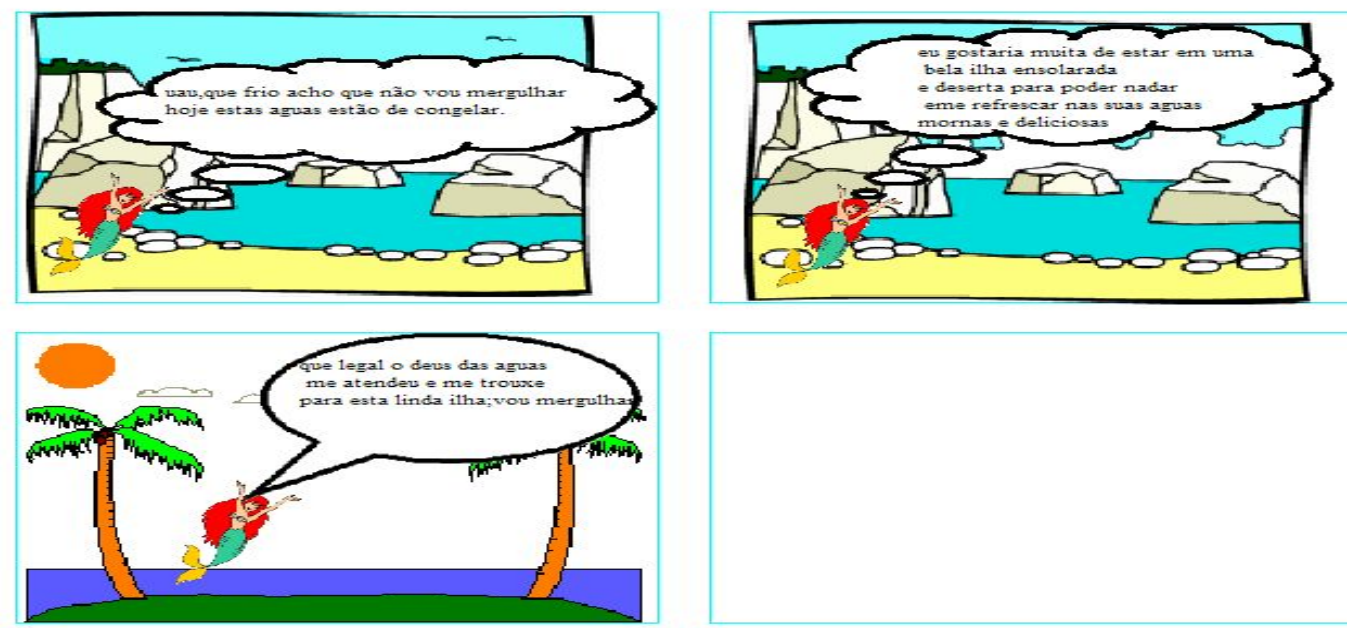

3B

Figura 3 - 3A e 3B. Exemplos de construção de histórias em quadrinhos, utilizando o software Hagaquê, voltado para este fim.

\section{Tertúlia Dialógica Virtual - Atividades segundo semestre 2008}

- Objetivo: Realizar a leitura do livro A Casa de Bonecas.

- Dinâmica: Durante o semestre, "decodificamos" coletivamente as marcações específicas a um gênero textual específico: peça de teatro, tentando compreender quando havia uma marcação de cena, uma descrição e as falas dos personagens. A dinâmica delineada foi a desenvolver uma leitura dramática, para depois discutir o trecho lido. Deu-se continuidade ao trabalho desenvolvido no primeiro semestre, no sentido de entremear à prática de leitura atividades utilizando tecnologias digitais

\section{Rotina 1}

- Realização, em um primeiro momento, de uma conversa informal sobre fatos da semana, andamento e retomada das atividades da semana anterior, etc.

- Realização de leitura de um trecho da peça e discuss.

- Realização de atividade envolvendo tecnologias digitais que mantivessem relação com a leitura desenvolvida ou com o projeto de intercâmbio Sem Fronteiras.

\section{Rotina 2}

- Atividade envolvendo tecnologias digitais e questão de narrativas, ou outras demandas vindas dos alunos.

O planejamento ia sendo alternando a rotina 1 e a rotina 2 , na medida da necessidade e do interesse dos alunos.

\section{Notas}

1) Os alunos receberam cópias do livro, mas percebemos que nem todos 
conseguiam realizar a leitura anteriormente aos encontros presenciais, por falta de tempo ou por outras dificuldades. Acabamos, assim, assumindo a leitura coletiva in loco como metodologia, e criamos uma dinâmica de distribuição de personagens para realização de uma "leitura dramática".

2) À medida que as "leituras dramáticas" prosseguiam, a peça de Ibsen, encenada por todos, ganhou ares de "folhetim". Nora, a personagem principal, já era nossa conhecida. "será que ela matou o próprio pai?" "O que acontecerá?" O exercício de leitura foi extremamente interessante. O grupo se ajudava quando um dos personagens "engasgava", tentando ler junto para descobrir que palavra era.

3) Um dos pontos mais interessantes foi a entrada do "blog" como uma ferramenta de registro da produção da leitura compartilhada. O recurso não havia sido considerado no planejamento, mas acabou sendo utilizado à medida que se sentiu necessidade de compartilhar, com os outros grupos que realizavam a atividade de tertúlia paralelamente a nós, o que estávamos entendendo do texto. Com esse intuito surgiu o blog http://tertuliasvirtuaiscmetpaulofreire.blogspot.com/, onde estão registrados notícias de como foram os encontros e alguns textos produzidos coletivamente sobre os nossos entendimentos do texto (Figura 4).

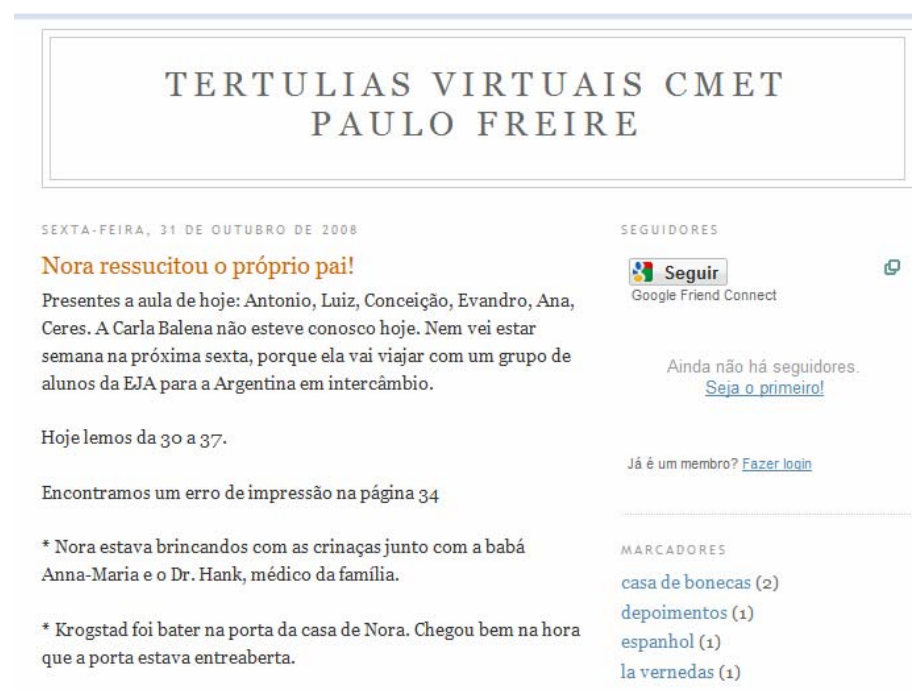

Figura 4 - Postagem do Blog http://tertuliasvirtuais-cmetpaulofreire.blogspot.com/ 
Nesse blog também foi possível disponibilizar um vídeo com uma cena lida pelo grupo (Figura 5)

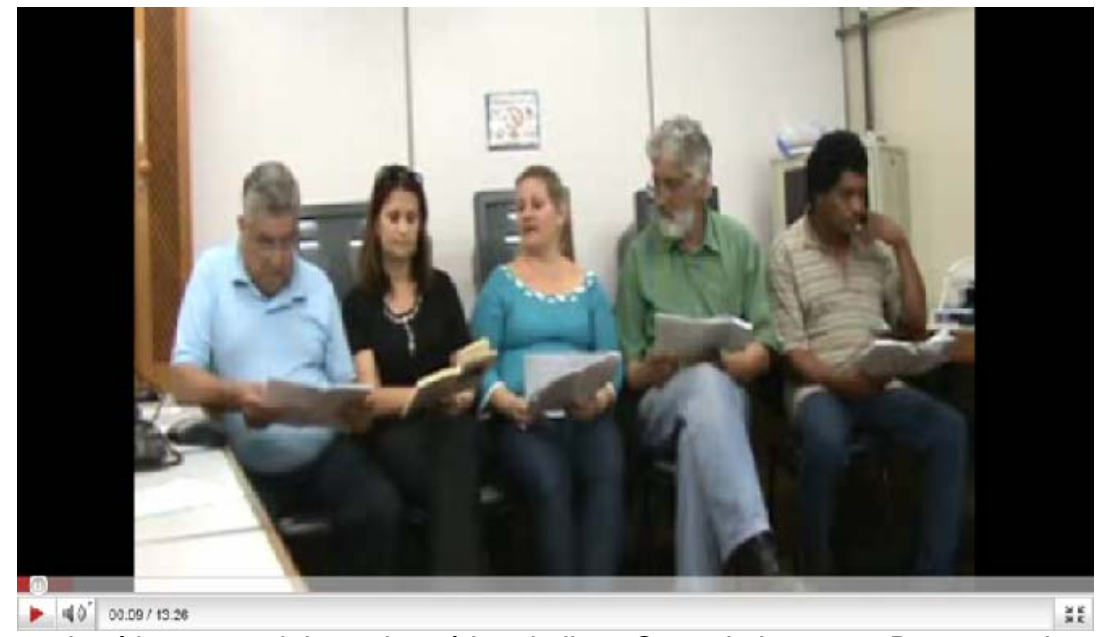

Figura 5 - Cena de vídeo com a leitura dramática do livro Casa de bonecas. Da esquerda para direita: Ney (Krogstad), Carla (Linde), Conceição (Nora), Antonio (Thorvald Helmer), Luís (Rank).

$\mathrm{Na}$ figura 6, encontra-se um quadro-síntese das ações que envolveram o projeto Tertúlias Dialógicas Virtuais durante o ano de 2008 no CMET Paulo Freire.

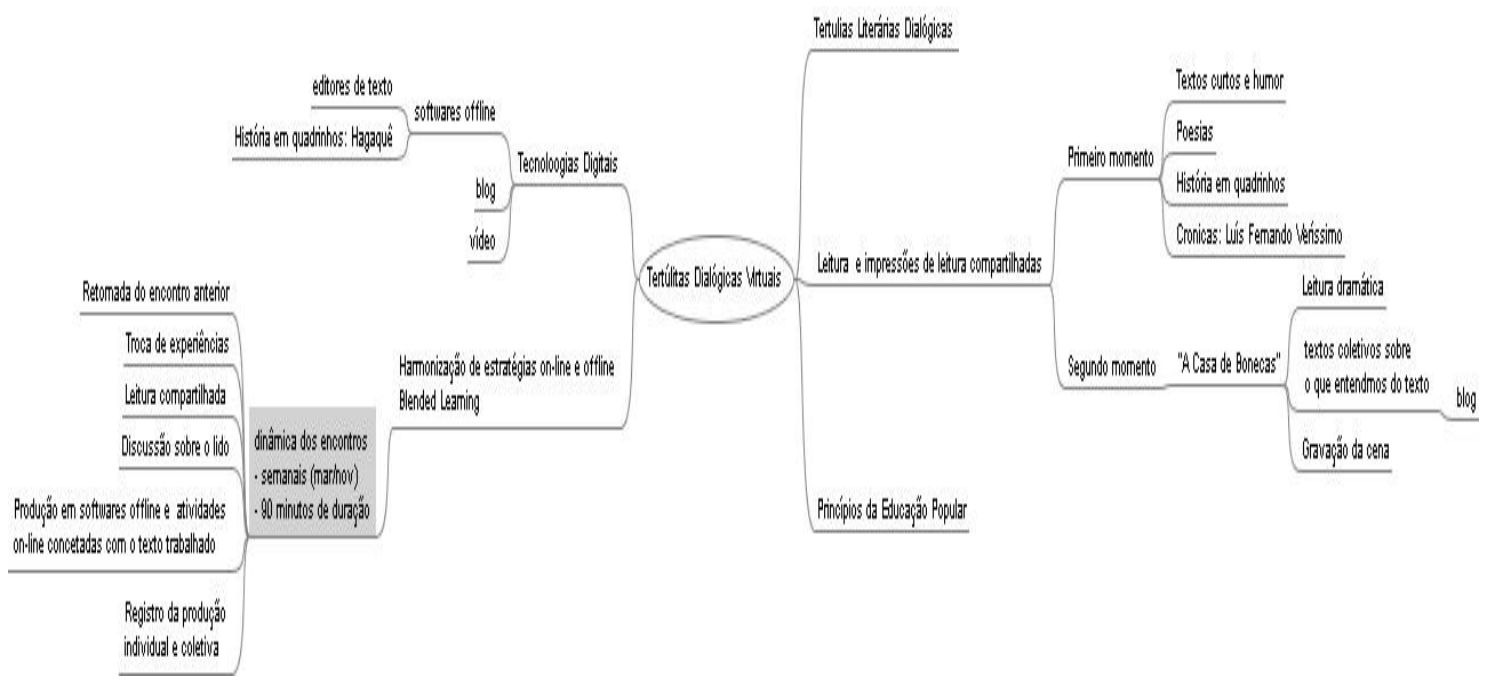

Figura 6 - Mapa do projeto de preparação para a webconferência Mil y Una Tertulias Literarias Dialógicas por Todo el Mundo, realizado no ano de 2008 no CMET Paulo Freire.

\section{Conclusões}

Os achados da experiência relatada apontam para a positividade de abordagens como às tertúlias literárias dialógicas como o estabelecimento de espaço de compartilhamento de leitura e de experiências que possibilitam a 
apropriação de textos literários.

A experiência também aponta para possibilidades de efetiva integração entre tecnologias digitais e aprendizagens dialógicas advindas de projetos como as tertúlias dialógicas virtuais, com aspectos de harmonização das tecnologias e interação, inspirados em princípios de blended learning. Ações desta natureza, ao fomentar aprendizado da leitura e da escrita, em meio impresso e digital, também parecem contribuir para uma dupla qualificação da inserção de alunos jovens e adultos, tanto na cultura escrita e quanto na cultura informatizada.

\section{Bibliografia}

PINA, A. B. Entornos de aprendizaje mixto en educación Superior. In: Revista Iberoamericana de Educación a Distância. Documento WEB.

http://www.utpl.edu.ec/ried/images/pdfs/volumen11/bartolome.pdf . Acessado em 02/06/2010

CHAIB, D. A ação comunicativa na educação musical de adultos: a tertúlia musical. IN: CONGRESSO DA ASSOCIAÇÃO NACIONAL DE PESQUISA E PÓS-GRADUAÇÃO EM MÚSICA, 16. Anais. Documento WEB.

http://www.anppom.com.br/anais/anaiscongresso_anppom_2006/CDROM/COM/01_Com_EdMus/sessao 05/01COM_EdMus_0502-147.pdf. Acessado em 22/11/2008

DONELLY, Roisin. Harmonizing technology with interaction in blended problem-based learning. In: Computers \& Education, 54, 350-359. 2010.

FACEPA. Manifiesto Por un Modelo Democrático de Alfabetización Mediática: De Receptores a Gestores de la información - proyecto e-quality. Documento WEB. http://www.facepa.org/PDF/ES/manifest_es.pdf . Acessado em 28.11.2008

FLECHA, R; MELLO, R. R. Tertúlia Literária Dialógica: compartilhando histórias. Presente! revista de educação - Ano 13 - nº 48 - Salvador, mar/2005 (p. 29 - 33).

FREIRE, F. Pedagogia do Oprimido. São Paulo: Ed. Paz e Terra. 47a. ed. 2005.

GRAHAN. C.R. Blended Learning Systems: Definition, Current Trends, and Future Directions. IN: BONK, C. J. \& GRAHAM, C. R. (Eds.). (in press). Handbook of blended learning: Global Perspectives, local designs. San Francisco, CA: Pfeiffer Publishing. 2004

GIROTTO, V. C. Tertúlia literária dialógica entre crianças e adolescentes: conversando sobre âmbitos da vida. Universidade Federal de São Carlos, 2007. Dissertação de Mestrado

MACDONALD, J. Blended learning and online tutoring: planning learner support and activity design. Burlington: Gower Publishing Company. 2a ed. 2008.

MELLO, R.R.; BATEL, T. H. BOGADO, A. M.; HORI, T. Tertúlia Literária Dialógica. CONGRESSO BRASILEIRO DE EXTENSÃO UNIVERSITÁRIA, 2. Anais. Belo Horizonte: UFMG. 2004 